\title{
Structure and Properties of Off-Stoichiometric Ba-Ga-Ge Selenide Glasses
}

\author{
A.W. Mao ${ }^{1, *}$, D.C. Kaseman ${ }^{1}$, B.G. Aitken ${ }^{2}$, S. Sen ${ }^{1}$ \\ ${ }^{1}$ Division of Materials Science, University of California at Davis, \\ Davis, CA 95616, USA \\ ${ }^{2}$ Glass Research Division, Corning Inc., Corning, NY 14831, USA \\ *Corresponding Author, email: awmao@ucdavis.edu
}




\begin{abstract}
Off-stoichiometric glasses in the Ba-Ga-Ge-Se system with Se excess or deficiency (BGGS \pm Se) are synthesized and their structure is characterized using Raman and multinuclear $\left({ }^{77} \mathrm{Se},{ }^{71} \mathrm{Ga}\right)$ magic-angle-spinning nuclear magnetic resonance (MAS NMR) spectroscopy. The results reveal that the structure of these off-stoichiometric $\mathrm{BGGS} \pm \mathrm{Se}$ glasses consists of a charge-compensated, partially covalent network of corner-sharing $(\mathrm{Ga} / \mathrm{Ge}) \mathrm{Se}_{4}$ tetrahedra where $\left[\mathrm{GaSe}_{4}\right]^{-}$tetrahedra charge balance the $\mathrm{Ba}^{2+}$ cations. Addition of excess Se to a stoichiometric BaSe- $\mathrm{Ga}_{2} \mathrm{Se}_{3}-\mathrm{GeSe}_{2}$ glass with BaSe: $\mathrm{Ga}_{2} \mathrm{Se}_{3}>1$ results in the formation of Se-Se linkages, while Se deficiency is accommodated via the formation of homopolar Ge-Ge bonds, in agreement with the continuously-alloyed structural scenario of purely covalent chalcogenide glasses. Such composition-dependent structural evolution is shown to be consistent with the corresponding variation in density and glass transition temperature.
\end{abstract}




\section{Introduction}

Chalcogenide glasses are important candidate materials for wide ranging technological applications in the areas of phase change memory, infra-red photonics, sensors and solid-state batteries [1-6]. Although many studies can be found in the literature that have focused on establishing structure-property relationships for network chalcogenide glasses in the system GeAs-P-X (X=S, Se, Te) [7-13], relatively little is known about such glasses that contain network modifying alkali and/or alkaline-earth elements [14-21]. In this regard, the ternary stoichiometric chalcogenide glasses in the system $\mathrm{M}_{2} \mathrm{Se}\left(\mathrm{M}^{\prime} \mathrm{Se}\right)-\mathrm{Ga}_{2} \mathrm{Se}_{3}-\mathrm{GeSe}_{2}\left(\mathrm{M}=\right.$ alkali, $\mathrm{M}^{\prime}=$ alkaline earth) are particularly interesting as they are isoelectronic with oxide glasses in the system $\mathrm{M}_{2} \mathrm{O}\left(\mathrm{M}^{\prime} \mathrm{O}\right)-\mathrm{Al}_{2} \mathrm{O}_{3}-\mathrm{SiO}_{2}$ that have been extensively studied in the literature.

The composition dependent changes in the structures of modified and chargecompensated $\mathrm{M}_{2} \mathrm{Se}\left(\mathrm{M}^{\prime} \mathrm{Se}\right)-\mathrm{Ga}_{2} \mathrm{Se}_{3}-\mathrm{GeSe}_{2}$ glasses can be potentially described using two different models. The first is the continuous-alloying model which is typically associated with network chalcogenide glasses $[12,13]$. In this structural model the constituent Group IV, V and VI atoms in the covalently bonded network are characterized by nearest-neighbor coordination numbers that are given by the $8-\mathrm{N}$ rule where $\mathrm{N}$ is the number of valence electrons. As a result, the structure of glasses at stoichiometric compositions such as $\mathrm{GeX}_{2}$ and $\mathrm{As}_{2} \mathrm{X}_{3}$ consist primarily of corner-sharing, heteropolar-bonded $\mathrm{GeX}_{4}$ and $\mathrm{AsX}_{3}$ coordination polyhedra. Off-stoichiometry in the form of excess $\mathrm{X}$ (chalcogen-excess) therefore results in the formation of homopolar $\mathrm{X}-\mathrm{X}$ bonds within the structural network, while a deficiency of $\mathrm{X}$ atoms results in the formation of metal-metal bonds to satisfy the 8-N rule. Such continuous alloying allows chalcogenide glasses to be formed over relatively wide ranges of compositions. 
The second structural model is the charge-compensated network scenario of oxide glasses such as those in the systems $\mathrm{M}_{2} \mathrm{O}\left(\mathrm{M}^{\prime} \mathrm{O}\right)-\mathrm{Al}_{2} \mathrm{O}_{3}-\mathrm{SiO}_{2}$ with more ionic character of bonding compared to chalcogenides. The compositional evolution of the structure of charge-compensated $\mathrm{M}_{2} \mathrm{O}\left(\mathrm{M}^{\prime} \mathrm{O}\right)-\mathrm{Al}_{2} \mathrm{O}_{3}-\mathrm{SiO}_{2}$ glasses is better described in terms of the ratio $\mathrm{R}=\mathrm{M}_{2} \mathrm{O}\left(\mathrm{M}^{\prime} \mathrm{O}\right): \mathrm{Al}_{2} \mathrm{O}_{3}$. For $\mathrm{R}=1$, every atom of oxygen introduced through $\mathrm{M}_{2} \mathrm{O}\left(\mathrm{M}^{\prime} \mathrm{O}\right)$ completes one formula unit of $\mathrm{Al}_{2} \mathrm{O}_{4}$, or two $\mathrm{AlO}_{4 / 2}$ tetrahedra, which effectively replaces two $\mathrm{SiO}_{4 / 2}$ units in the tetrahedral network. $\mathrm{R}>1$ thus implies that there is an excess of oxygen atoms, which break the cornershared tetrahedral network to form non-bridging oxygen. Similarly, $\mathrm{R}<1$ implies a deficiency of oxygen atoms, which causes the formation of five-fold and six-fold coordinated Al [22].

Recent studies by us [23-27] have addressed the structure-property relationships in stoichiometric glasses in the systems $\mathrm{Na}_{2} \mathrm{Se}-\mathrm{Ga}_{2} \mathrm{Se}_{3}-\mathrm{GeSe}_{2} \quad$ (NGGS) [26] and BaSe- $\mathrm{Ga}_{2} \mathrm{Se}_{3}-\mathrm{GeSe}_{2}$ (BGGS) [23, 25] to elucidate the structural effects of modifier addition and to determine which of the two aforementioned scenarios provides a better description of the structure of modified chalcogenide glasses. These studies have demonstrated that the stoichiometric $\mathrm{Ga}_{2} \mathrm{Se}_{3}-\mathrm{GeSe}_{2}$ (GGS) glasses generally behave according to the continuousalloying structural scenario while the BGGS and NGGS glasses exhibit aspects of both structural models. In particular, glasses in the latter two systems tend to form Ge-Ge homopolar bonds for compositions with $\mathrm{R}<1$ where $\mathrm{R}=\mathrm{Na}_{2} \mathrm{Se}(\mathrm{BaSe}): \mathrm{Ga}_{2} \mathrm{Se}_{3}$, while non-bridging Se are thought to form in glasses with $\mathrm{R}>1$. It should be noted that since addition of $\mathrm{Na}_{2} \mathrm{Se}$ or $\mathrm{BaSe}$ introduces Se atoms into the structure, $R>1(R<1)$ implies an excess (deficiency) of Se with respect to the amount required to satisfy heteropolar tetrahedral bonding for $\mathrm{Ga}$ and $\mathrm{Ge}$ atoms in the network. In this study, we investigate the structural characteristics of off-stoichiometric BGGS \pm Se glasses with fixed R using Raman and nuclear magnetic resonance (NMR) spectroscopy. Given the lack 
of studies in the literature concerning non-stoichiometric chalcogenide glasses containing $M\left(M^{\prime}\right)$-type modifiers, the objective of this investigation is two-fold, namely: 1) to determine the extent of glass formation and, 2) to elucidate the structural role of Se-excess or deficiency, in modified selenide networks with off-stoichiometry. The composition-dependent structural evolution of these glasses is then linked to the corresponding variation in density and glass transition temperature $T_{g}$.

\section{Experimental}

\subsection{Sample preparation}

Glasses in the system $(\mathrm{BaSe})_{\mathrm{x}}-\left(\mathrm{Ga}_{2} \mathrm{Se}_{3}\right)_{100-\mathrm{x}-\mathrm{y}}-\left(\mathrm{GeSe}_{2}\right)_{\mathrm{y}} \pm(\mathrm{Se})_{\mathrm{z}}$ were synthesized using the melt-quench method where special care was taken to minimize the uptake of oxygen by elemental Ba. As a first step, the Ba-free Ga-Ge-Se precursor alloy was prepared by batching the constituent elements in a dry nitrogen atmosphere. The batches were loaded into fused silica ampules evacuated to $\sim 10^{-5}$ torr. Loaded ampules were flame sealed and placed into a rocking furnace, and the temperature was slowly ramped to $950{ }^{\circ} \mathrm{C}$ over several hours. The melts were rocked for $\sim 1.5$ days and water-quenched. In the second step, these GaGeSe precursor alloys were mixed in a dry nitrogen atmosphere with the appropriate amount of $\mathrm{Ba}$ to create $10 \mathrm{~g}$ final batches that were loaded into fused-silica ampules whose inner walls were pre-coated with a thin layer of Si by vapor deposition. These ampules were then evacuated and flame-sealed. The temperature was then slowly ramped to $900{ }^{\circ} \mathrm{C}$ in order to minimize corrosion of the Si film. The melts were rocked for $\sim 3$ hours, followed by quenching in water.

For purposes of comparison, the compositions of off-stoichiometric BGGS \pm Se glasses are based on previously studied stoichiometric BGGS glasses, where $y=60$ and 75 [23, 25]. In 
this way, four series of off-stoichiometric glasses were synthesized with $y=60$, where $x=7.5$, 15, 25, and 32.5. Similarly, three series were synthesized with $y=75$, where $x=5,12.5$, and 20 . The deviation of Se from stoichiometry expressed as z (in mol\%) ranged between -40 and +20 and was calculated relative to the Se content in the corresponding stoichiometric glass. For example, a BGGS \pm Se glass of composition $\left(\mathrm{BaSe}_{20}-\left(\mathrm{Ga}_{2} \mathrm{Se}_{3}\right)_{5}-\left(\mathrm{GeSe}_{2}\right)_{75}+(\mathrm{Se})_{10}\right.$ contains $10 \%$ more total moles of Se compared to the stoichiometric glass $(\mathrm{BaSe})_{20}-\left(\mathrm{Ga}_{2} \mathrm{Se}_{3}\right)_{5}-\left(\mathrm{GeSe}_{2}\right)_{75}$. The glass compositions synthesized in this study are reported in Table 1 and in graphical form in Figure 1. These glass compositions will hereafter be referred to using the notation (y) $\mathrm{Ba}(\mathrm{x})+(\mathrm{z}) \mathrm{Se}$, where $\mathrm{x}$ is the BaSe content, $\mathrm{y}$ is the $\mathrm{GeSe}_{2}$ content, and $\mathrm{z}$ is the offstoichiometric content of Se, all in mole percent.

\subsection{Raman spectroscopy}

The Raman spectra of all glasses were collected using a Bruker RFS 100/S Fouriertransform (FT) Raman spectrometer equipped with a Nd:YAG laser operating at a wavelength of $1064 \mathrm{~nm}$. Each Raman spectrum is the average of 32-256 scans collected in backscattering geometry using a resolution of $4 \mathrm{~cm}^{-1}$ and laser power ranging between 32 and $75 \mathrm{~mW}$.

\subsection{NMR spectroscopy}

All ${ }^{77} \mathrm{Se}$ and ${ }^{71} \mathrm{Ga}$ NMR spectroscopic measurements were carried out at an external magnetic field of $11.7 \mathrm{~T}$ using a Bruker Avance spectrometer operating at the Larmor frequencies of 152.5 and $95.3 \mathrm{MHz}$ for ${ }^{71} \mathrm{Ga}$ and ${ }^{77} \mathrm{Se}$, respectively. The ${ }^{77} \mathrm{Se}$ magic-anglespinning (MAS) NMR spectra were collected using a rotor synchronized Hahn-echo pulse

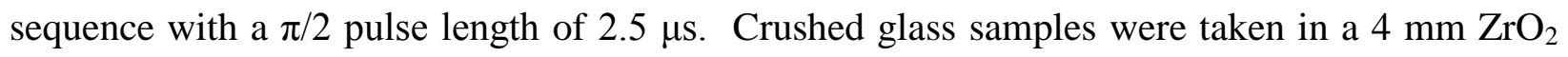
rotor and were spun at $12.5 \mathrm{kHz}$. A recycle delay of $120 \mathrm{~s}$ was employed for all glasses and no differential relaxation was observed when the delay was increased to 300 s. $300-500$ scans were 
averaged and Fourier transformed to obtain each ${ }^{77}$ Se MAS NMR spectrum. All ${ }^{77}$ Se chemical shifts were referenced to the isotropic ${ }^{77} \mathrm{Se}$ chemical shift $\delta_{\text {iso }}$ of crystalline $\left(\mathrm{NH}_{4}\right)_{2} \mathrm{SeO}_{4}$ $\left(\delta_{\text {iso }}=1040.2 \mathrm{ppm}\right)[28]$.

High-resolution ${ }^{71} \mathrm{Ga}$ NMR spectra were obtained using the quadrupolar magic-angleturning (QMAT) pulse sequence as reported in the literature [29]. Crushed samples were taken in a $7 \mathrm{~mm} \mathrm{ZrO}_{2}$ rotor and spun at $7 \mathrm{kHz}$. QMAT NMR is a two-dimensional technique that uses linearly varying delays between ten central transition selective pulses to yield an "infinite" spinning speed MAS spectrum. The central transition selective $\pi / 2$ and $\pi$ pulse lengths were 1.3 and $2.6 \mu$ s respectively, corresponding to a radio frequency field of $112 \mathrm{kHz}$. A total of $32 \mathrm{t}_{1}$ increments were employed over a single rotor period. $10 \mathrm{k}$ transients were collected for each $\mathrm{t}_{1}$ slice using a $0.2 \mathrm{~s}$ relaxation delay between each transient, allowing a full $2 \mathrm{D}$ spectrum to be acquired in under $18 \mathrm{hrs.}$ The "infinite" spinning speed ${ }^{71}$ Ga MAS NMR spectra were obtained through summation of the $32 t_{1}$ increments after shearing and Fourier transforming both direct and indirect dimensions. All ${ }^{71}$ Ga chemical shifts were referenced to the isotropic chemical shift of $1 \mathrm{M} \mathrm{Ga}\left(\mathrm{NO}_{3}\right)_{3}\left(\delta_{\mathrm{iso}}=0 \mathrm{ppm}\right)$.

\subsection{Density measurements}

Density measurements were carried out using a Micromeritics AccuPyc II gas expansion pycnometer under a helium environment of $6 \mathrm{~N}$ purity. Approximately $0.5-2.0 \mathrm{~g}$ of each sample was loaded into a $1 \mathrm{~cm}^{3}$ cup. Reported densities are averages of 10 consecutive measurements at $20{ }^{\circ} \mathrm{C}$ and are determined to within $\pm 0.005 \mathrm{~g} / \mathrm{cm}^{3}$.

\subsection{Differential scanning calorimetry (DSC)}

Conventional DSC scans were taken using a Mettler-Toledo DSC1 calorimeter. Scans were performed in a flowing nitrogen environment on $15-20 \mathrm{mg}$ of sample loaded into $40 \mu \mathrm{L}$ 
aluminum crucibles. The glass transition temperature $T_{g}$ is determined as the onset of the glass transition region, when heating at a rate of $10 \mathrm{~K} / \mathrm{min}$.

\section{Results}

\subsection{Mapping the glass-forming region in the BGGS \pm Se system with off-stoichiometry}

Figure 1 shows the tentative glass-forming region, as determined by the lack of any detectable evidence of crystallization in the powder x-ray diffraction patterns of BGGS and BGGS \pm Se glasses. It was shown in previous studies of stoichiometric BGGS glasses [23, 25] that glass formation is favored toward the edges of the ternary composition space - that is, toward pure $\mathrm{GeSe}_{2}$ and the binary tie lines between $\mathrm{Ga}_{2} \mathrm{Se}_{3}-\mathrm{GeSe}_{2}$ and $\mathrm{BaSe}-\mathrm{GeSe}_{2}$, but away from the region near $\mathrm{R}=1$, i.e. $\mathrm{BaSe}: \mathrm{Ga}_{2} \mathrm{Se}_{3}=1: 1$. A lack of glass formation near $\mathrm{R}=1$ was also observed in the analogous sulfide system $\mathrm{BaS}-\mathrm{Ga}_{2} \mathrm{~S}_{3}-\mathrm{GeS}_{2}$ [17] and it suggests that in both the sulfide and selenide systems, devitrification near the center of the ternary diagram might be attributed to the existence of crystalline phases such as $\mathrm{Ba}_{2.7} \mathrm{Ga}_{5.4} \mathrm{Ge}_{3.6} \mathrm{~S}_{18}$ [16] and $\mathrm{BaGa}_{2} \mathrm{GeX}_{6}$ $(\mathrm{X}=\mathrm{S}, \mathrm{Se})[30,31]$, where the ratio of $\mathrm{BaX}: \mathrm{Ga}_{2} \mathrm{X}_{3}$ is $1: 1$.

Addition of BaSe to binary $\mathrm{Ga}_{2} \mathrm{Se}_{3}-\mathrm{GeSe}_{2}$ slightly increases the maximum allowable content of $\mathrm{Ga}_{2} \mathrm{Se}_{3}$ for glass formation from $30 \mathrm{~mol} \%$ to at least $32.5 \mathrm{~mol} \%$, which is consistent with the similar effect of the addition of $\mathrm{Na}_{2} \mathrm{Se}$ as reported in a recent study on glasses in the stoichiometric $\mathrm{Na}_{2} \mathrm{Se}-\mathrm{Ga}_{2} \mathrm{Se}_{3}-\mathrm{GeSe}_{2}$ system [26]. Along the BaSe-GeSe ${ }_{2}$ binary, there have been reports of crystalline compounds such as $\mathrm{Ba}_{2} \mathrm{GeSe}_{4}$ [32] and $\mathrm{Ba}_{2} \mathrm{Ge}_{2} \mathrm{Se}_{5}$ [33]; however, information about glass formation remains lacking. The same is true for the $\mathrm{BaSe}-\mathrm{Ga}_{2} \mathrm{Se}_{3}$ binary, which contains crystalline compounds such as $\mathrm{BaGa}_{2} \mathrm{Se}_{4}[34], \mathrm{BaGa}_{4} \mathrm{Se}_{7}[35,36], \mathrm{Ba}_{5} \mathrm{Ga}_{2} \mathrm{Se}_{8}$ [37], and $\mathrm{Ba}_{5} \mathrm{Ga}_{4} \mathrm{Se}_{10}[38]$. 
For the off-stoichiometric Se-excess or Se-deficient BGGS \pm Se compositions that are above or below the plane of the ternary $\mathrm{BaSe}-\mathrm{Ga}_{2} \mathrm{Se}_{3}-\mathrm{GeSe}_{2}$ composition space, the trend in glass-forming ability changes only slightly. In general, the glass formation tends to be favored for compositions that contain an excess of Se over stoichiometry or contain a high ratio of BaSe: $\mathrm{Ga}_{2} \mathrm{Se}_{3}$. The largest glass-forming ranges with respect to Se content were observed for the two series based on the stoichiometric glasses $75 \mathrm{Ba} 20+0 \mathrm{Se}$ and $60 \mathrm{Ba} 32.5+0 \mathrm{Se}$, where glasses could be made for $\mathrm{z}$ values between -30 and +20 for the former and between -20 and +20 for the latter. Therefore, in the subsequent discussion we specifically focus on the structure-property relationships in glasses that belong to these two series.

\subsection{Raman spectroscopy}

The Raman spectra of the two series with the greatest number of glassy samples, i.e. $75 \mathrm{Ba} 20+(\mathrm{z}) \mathrm{Se}$ and $60 \mathrm{Ba} 32.5+(\mathrm{z}) \mathrm{Se}$, are shown in Figures 2 and 3 and are normalized to the intensity of the peak near $200 \mathrm{~cm}^{-1}$. Regardless of composition, all Raman spectra exhibit three general regions that are characteristic of vitreous Ga-Ge-Se networks [39-41]: i) a broad, relatively featureless band extending from $\sim 50 \mathrm{~cm}^{-1}$ to $160 \mathrm{~cm}^{-1}$; ii) a group of three peaks located at $\sim 175 \mathrm{~cm}^{-1}, \sim 200 \mathrm{~cm}^{-1}$, and $\sim 215 \mathrm{~cm}^{-1}$; and iii) a high wavenumber band extending from about $225 \mathrm{~cm}^{-1}$ to $340 \mathrm{~cm}^{-1}$. The peak at $200 \mathrm{~cm}^{-1}$ in region (ii) is generally the major feature in the Raman spectra of binary $\mathrm{Ga}_{2} \mathrm{Se}_{3}-\mathrm{GeSe}_{2}$ glasses and corresponds to the symmetric $\mathrm{A}_{1}$ vibrations of corner-sharing $(\mathrm{CS})(\mathrm{Ga} / \mathrm{Ge}) \mathrm{Se}_{4}$ tetrahedra that make up the backbone of the structural network. The neighboring peaks at $175 \mathrm{~cm}^{-1}$ and $215 \mathrm{~cm}^{-1}$ can be attributed to the vibrations of Ge-Ge bonds in ethane-like $\left(\mathrm{Se}_{3}\right) \mathrm{Ge}-\mathrm{Ge}\left(\mathrm{Se}_{3}\right)$ units and Ge-Se bonds in edge-sharing (ES) $(\mathrm{Ga} / \mathrm{Ge}) \mathrm{Se}_{4}$ tetrahedra, respectively. In region (i), the low wavenumber band contains various bond-bending modes, while the high wavenumber band in region (iii) consists of many 
overlapping bands that may include the symmetric stretching of Se chains near $270 \mathrm{~cm}^{-1}$ and the asymmetric vibration of $\mathrm{GeSe}_{4}$ tetrahedra near $310 \mathrm{~cm}^{-1}$. It should be noted at this point that the relatively sharp feature exhibited by all of the Raman spectra near $85 \mathrm{~cm}^{-1}$ is a background signal from the sample holder.

As excess Se is added to the stoichiometric glass 75Ba20+0Se (Fig. 2), the intensities of both peaks near $175 \mathrm{~cm}^{-1}$ and $215 \mathrm{~cm}^{-1}$ (henceforth denoted as $\mathrm{I}_{175}$ and $\mathrm{I}_{215}$ ) decrease. $\mathrm{I}_{175}$ decreases abruptly to zero as $\mathrm{z}$ increases from 0 to $\geq+10$, while the decrease in $\mathrm{I}_{215}$ is more gradual such that residual intensity remains even at $\mathrm{z}=+20$. Additionally, increasing $\mathrm{z}$ results in the appearance and progressive growth of a new band near $265 \mathrm{~cm}^{-1}$. On the other hand, for Sedeficient glasses with negative $\mathrm{z}, \mathrm{I}_{215}$ again decreases to zero for $\mathrm{z}<-10$ while $\mathrm{I}_{175}$ shows a sharp increase with decreasing values of $\mathrm{z}$ and even exceeds the intensity of the primary peak $\left(\mathrm{I}_{200}\right)$ for $\mathrm{z}<-20$. Increasing Se deficiency (decreasing $\mathrm{z}$ ) also results in a continuous increase of the intensities of regions (i) and (iii). Since all spectra are normalized to $I_{200}$, and the ratio of the intensities in regions (i) and (iii) remains approximately constant, this observation may alternatively be interpreted as a continuous decrease in $\mathrm{I}_{200}$. The Raman spectra of glasses in the 60Ba32.5+(z)Se series (Fig. 3) largely exhibit the same trends seen in the $75 \mathrm{Ba} 20+(\mathrm{z})$ Se series, with the most notable differences being the lack of intensity near $175 \mathrm{~cm}^{-1}$ at $\mathrm{z}=0$ as well as less definition in the peak shoulders near $\sim 215 \mathrm{~cm}^{-1}$ and $240 \mathrm{~cm}^{-1}$.

\subsection{NMR spectroscopy}

The ${ }^{77}$ Se MAS NMR spectra of three representative glasses in the $75 \mathrm{Ba} 20+(\mathrm{z})$ Se series with $\mathrm{z}=+20$, 0, and -30 are compared in Figure 4. These spectra exhibit a broad lineshape extending from about $750 \mathrm{ppm}$ to $50 \mathrm{ppm}$ that resembles Se in glassy Ge-Se and Ga-Ge-Se networks. In general, these spectra can be modeled using a set of three peaks centered near 600, 
400, and 250 ppm that respectively correspond to the following Se environments: 1) Ge-Se-Ge in ES $(\mathrm{Ga} / \mathrm{Ge}) \mathrm{Se}_{4}$ tetrahedra or Ge-Se-Se linkages between chains and tetrahedra, 2) Ge-Se-Ge in $\mathrm{CS}(\mathrm{Ga} / \mathrm{Ge}) \mathrm{Se}_{4}$ tetrahedra, and 3) Ge-Se-Ge in $\left(\mathrm{Se}_{3}\right) \mathrm{Ge}-\mathrm{Ge}\left(\mathrm{Se}_{3}\right)$ ethane-like units that contain Ge-Ge homopolar bonds $[9,24,27,42]$. In the ${ }^{77}$ Se MAS NMR spectrum of the $75 \mathrm{Ba} 20+0 \mathrm{Se}$ glass, the lineshape is essentially symmetric and centered near $400 \mathrm{ppm}$ with possible small contributions from the resonances near $600 \mathrm{ppm}$ and $250 \mathrm{ppm}$. As $\mathrm{z}$ is increased from 0 to +20 , the ${ }^{77}$ Se MAS NMR spectrum remains largely the same except for a small increase in intensity near $\sim 650 \mathrm{ppm}$, which makes the line shape slightly wider and more asymmetric. In contrast, when $\mathrm{z}$ is decreased from 0 to -30 , the center of gravity of the ${ }^{77}$ Se MAS NMR line shape shifts significantly to $\sim 250 \mathrm{ppm}$ and broadens, due to a drastic increase in the contribution from resonances at lower frequencies. The ${ }^{77} \mathrm{Se}$ MAS NMR spectra of the $60 \mathrm{Ba} 32.5+(\mathrm{z}) \mathrm{Se}$ glasses with $\mathrm{z}=+20,0$, and -20 show similar behavior as a function of $\mathrm{z}$ (Fig. 5).

Figure 6 shows the ${ }^{71} \mathrm{Ga}$ central transition QMAT NMR spectra of the $75 \mathrm{Ba} 20+(\mathrm{z}) \mathrm{Se}$ glasses with $\mathrm{z}=+20$ and -30 . These spectra, unlike their MAS counterparts, are free of spinning sidebands and are characterized by a single resonance that exhibits a maximum near $130 \mathrm{ppm}$ and a low frequency tail that is typical of MAS NMR spectra of quadrupolar nuclides in disordered materials where it is associated with a distribution of quadrupolar coupling constants $\mathrm{C}_{\mathrm{Q}}[43,44]$. Simulation of the lineshape using the Czjzek model of distribution of $\mathrm{C}_{\mathrm{Q}}$ in the software DMfit [45] yields an isotropic chemical shift $\delta_{\text {iso }} \approx 180 \mathrm{ppm}$ and a quadrupolar coupling constant $\mathrm{C}_{\mathrm{Q}} \approx 10 \mathrm{MHz}$, which is in good agreement with the parameters reported for the ${ }^{71} \mathrm{Ga}$ MAS NMR spectra corresponding to the tetrahedral $\mathrm{GaSe}_{4}$ environment found in stoichiometric BGGS glasses [25]. As a result, it seems reasonable to conclude that the nearest-neighbor coordination environment of $\mathrm{Ga}$ atoms remains unaffected by the departure from stoichiometry. 


\subsection{Glass transition temperature $T_{g}$}

The $T_{g}$ of glasses in the 75Ba20+(z)Se series are shown in Figure 7, as the most complete and representative set for the off-stoichiometric BGGS \pm Se glasses. The $T_{g}$ values range between $\sim 280{ }^{\circ} \mathrm{C}$ and $400{ }^{\circ} \mathrm{C}$. As $|\mathrm{z}|$ increases, i.e. as the Se content deviates from stoichiometry, the $T_{g}$ decreases from the maximum value of about $395{ }^{\circ} \mathrm{C}$ for $\mathrm{z}=0$. In glasses with Se excess $(z>0)$ the $T_{g}$ drops precipitously by over $100{ }^{\circ} \mathrm{C}$ as $\mathrm{z}$ increases from 0 to +20 . In the Se-deficient regime $(\mathrm{z}<0), T_{g}$ decreases less rapidly from $\mathrm{z}=0$ to $\mathrm{z}=-20$ and subsequently levels off slightly around $\mathrm{z}=-30$.

\subsection{Glass density}

Density and molar volume data for glasses in the $75 \mathrm{Ba} 20+(\mathrm{z}) \mathrm{Se}$ series are shown in Figure 8. The densities of all glasses range between $\sim 4.4 \mathrm{~g} / \mathrm{cm}^{3}$ and $4.9 \mathrm{~g} / \mathrm{cm}^{3}$ and exhibit a monotonic drop with increasing $\mathrm{z}$, although the rate of change is lower in the Se-excess regime compared to that in the Se-deficient regime. Molar volume shows an exactly opposite trend compared to density.

\section{Discussion}

When taken together, both the Raman and NMR spectra indicate that the structure of offstoichiometric BGGS \pm Se glasses with an excess or deficiency of Se is characterized by the same network of primarily corner-sharing and some edge-sharing $(\mathrm{Ga} / \mathrm{Ge}) \mathrm{Se}_{4 / 2}$ tetrahedra found in the

stoichiometric BGGS and GGS glasses. In this network, Ga and Ge both adopt four-fold coordination, regardless of composition, while Se primarily adopts two-fold coordination [41, 46]. The concentration of homopolar Ge-Ge bonds in Se-deficient BGGS \pm Se glasses with $\mathrm{z}<0$ decreases upon addition of $\mathrm{Se}$ and becomes negligible in the stoichiometric composition with 
$\mathrm{z}=0$, as indicated by the intensities of the Raman band near $175 \mathrm{~cm}^{-1}$ and of the low-frequency component in the ${ }^{77}$ Se MAS NMR spectra near 250 ppm (Figs. 2-5). Se-excess BGGS \pm Se glasses with $\mathrm{z}>0$ contain Se-Se linkages, as evidenced by an increase in the intensity of the Raman band near $265 \mathrm{~cm}^{-1}$ in these glasses with increasing Se concentration. This conclusion is consistent with the observation of an increase in the intensity near $\sim 650 \mathrm{ppm}$ in the ${ }^{77} \mathrm{Se}$ MAS NMR spectra of Se-excess BGGS \pm Se glasses that corresponds to Se-Se-Ge/Ga environments. However, the lack of any significant intensity in these ${ }^{77}$ Se MAS NMR spectra in the region 750 850 ppm suggests the absence of significant concentration of Se-Se-Se environments, i.e. longer Se chains in these Se-excess glasses. Finally, the content of ES tetrahedra decreases with any deviation from the $\mathrm{z}=0$ composition in either direction. This fact is most apparent in the Raman spectra, which show a decrease in $\mathrm{I}_{215}$ with increasing $|\mathrm{z}|$. All in all, these trends suggest that the structure of $\mathrm{BGGS} \pm \mathrm{Se}$ glasses behaves in accordance with the continuously-alloyed structural scenario of chalcogenide glasses.

Although the chalcogenide structural scenario effectively describes the structural evolution of off-stoichiometric $\mathrm{BGGS} \pm \mathrm{Se}$ glasses as a function of increasing excess or deficiency of Se, it may be noted that the stoichiometric BGGS glasses are electronically analogous to the alkaline-earth aluminosilicate glasses. Therefore, as mentioned earlier, it is informative to also consider the charge-compensated structural scenario of oxide glasses within the context of the structural evolution of stoichiometric and off-stoichiometric BGGS $( \pm \mathrm{Se})$ glasses in terms of the ratio $\mathrm{R}=\mathrm{BaSe}: \mathrm{Ga}_{2} \mathrm{Se}_{3}$. Raman and NMR spectroscopic results have shown that Ge-Ge homopolar bonds exist in both stoichiometric and off-stoichiometric BGGS $( \pm$ Se $)$ glasses with $\mathrm{R}<1$ and that their concentration tends to increase in the former with decreasing $R$, and in the latter with increasing Se deficiency at a constant $R[25,26]$. On the 
other hand, similar to their alkaline-earth aluminosilicate counterparts, non-bridging $\mathrm{Se}$ (NBSe) have been suggested to form in stoichiometric BGGS glasses with $\mathrm{R}>1$ [25]. In particular, as the molar concentration of BaSe exceeds that of $\mathrm{Ga}_{2} \mathrm{Se}_{3}$ in stoichiometric BGGS glasses, the glass structure contains more Se atoms than are needed to satisfy the fourfold coordination of $\mathrm{Ga}$ atoms, which results in the formation of NBSe. In contrast to the stoichiometric glasses, the accommodation of excess Se in off-stoichiometric BGGS \pm Se glasses with $\mathrm{R}>1$ is accomplished via the formation of Se-Se homopolar bonds rather than that of NBSe atoms. While the trend in off-stoichiometric BGGS \pm Se glasses with $\mathrm{R}<1$ is less clear due to the limited glass-forming region, preliminary evidence from Raman spectroscopy indicates that Se-excess in these glasses also results in the formation of Se-Se bonds instead of NBSe atoms (Fig. 9). Therefore, it is clear that stoichiometry plays an important role in the Se accommodation mechanism in BGGS $( \pm$ Se $)$ glasses.

It is reasonable to argue that the observed difference in Se accommodation mechanism between the stoichiometric and off-stoichiometric BGGS $( \pm \mathrm{Se})$ glasses with $\mathrm{R}>1$ stems from the ionic vs. covalent nature of bonding in these glass-forming systems. Given the difference in electronegativity between $\mathrm{Ba}(0.9)$ and $\mathrm{Se}(2.4)$, it is likely that $\mathrm{Ba}^{2+}$ ions in compensated BGGS( \pm Se $)$ networks with $\mathrm{R} \geq 1$ are charge balanced by $\left[\mathrm{GaSe}_{4}\right]^{-}$tetrahedra as in the case of crystalline $\mathrm{BaGa}_{2} \mathrm{Se}_{4}$ [34]. A similar charge balancing role has also been suggested in the literature for $\mathrm{MS}_{-} \mathrm{Ga}_{2} \mathrm{~S}_{3}(\mathrm{M}=\mathrm{Ca}, \mathrm{Sr}, \mathrm{Ba})$ glasses where the positive charge on the $\mathrm{M}^{2+}$ cation is balanced by the negative charge on the $\left[\mathrm{GaS}_{4}\right]^{-}$tetrahedra [47]. The partially ionic nature of the Ga-Se bonds was also suggested in crystalline GaSe [48]. Furthermore, a study on rare-earth and Ga doped Ge-As-S and Ge-Sb-Se glasses indicated that the positively charged rare-earth ions tend to be preferentially located near $\left[\mathrm{Ga}(\mathrm{S} / \mathrm{Se})_{4}\right]^{-}$tetrahedra $[49,50]$. On the other hand, the 
formation of the charge-neutral, covalent network in bulk Ga-containing chalcogenide glasses (e.g. in the $\mathrm{Ga}_{2} \mathrm{Se}_{3}-\mathrm{GeSe}_{2}$ system) is often explained on the basis of dative-covalent bonds between $\mathrm{Ga}$ and the chalcogen element $[51,52]$. In this case, $\mathrm{Ga}$ forms three covalent bonds with Se using its three valence electrons, while the fourth dative-covalent bond is formed between Ga and Se by exploiting a lone electron pair that originated on Se. This bonding configuration allows the Ga-Se bonds to retain a more covalent character, and is related to the formation of three-coordinated Se species [24, 27]. It is interesting to observe that the ioniccovalent character of the Ga-Se bonds may also be related to the higher affinity for the formation of heteropolar Ga-Se bonds compared to Ge-Se bonds, because the energy of the Ga-Se bond (65 $\mathrm{kcal} / \mathrm{mol}$ ) is larger than the covalent Ge-Se bonds (55.4 kcal/mol) [53]. A direct consequence of this affinity is the preferential formation of Ge-Ge bonds over $\mathrm{Ga}-\mathrm{Ga}$ or $\mathrm{Ga}-\mathrm{Ge}$ bonds in stoichiometric BGGS glasses with R $<1$ or in Se-deficient off-stoichiometric BGGS \pm Se glasses with $\mathrm{R}>1$ [25]. On a related note, this preference for the formation of Ge-Ge bonds over other less stable metal-metal bonds involving Ga or Ba may explain the wide range of Se-deficiency that can be accommodated by BGGS \pm Se glasses with $\mathrm{R}>1$ (Table 1).

The chalcogenide-like structural behavior of the off-stoichiometric BGGS \pm Se glasses with the formation of homopolar Se-Se (Ge-Ge) bonds in Se-excess (Se-deficient) regime is nicely consistent with the composition dependence of $T_{g}$. The sharper decrease in $T_{g}$ with increasing $\mathrm{z}$ in the region where $\mathrm{z}>0$ (Se-excess) is consistent with the formation of $\mathrm{Se}-\mathrm{Se}$ linkages, while the shallower decrease in $T_{g}$ with decreasing $\mathrm{z}$ in the region where $\mathrm{z}<0$ (Sedeficient) can be attributed to the formation of homopolar Ge-Ge bonds (Fig. 7). This observation is in excellent agreement with the behavior shown by off-stoichiometric Ge-Se glasses [13]. The trends in the density and molar volume of these off-stoichiometric BGGS $\pm \mathrm{Se}$ 
glasses are also consistent with this structural scenario in the sense that the linear trends in the variation of density and molar volume with $\mathrm{z}$ changes slope near $\mathrm{z}=0$ (Fig. 8) which coincides with the shift in the nature of the homopolar bonds in the structure from Ge-Ge to Se-Se. In slight contrast to the off-stoichiometric $\mathrm{BGGS} \pm$ Se glasses, the Ge-Se glasses show a minimum (maximum) in density (molar volume) near the stoichiometric composition as a function of the degree of Se deficiency or excess since the formation of both Ge-Ge and Se-Se homopolar bonds tends to decrease molar volume or increase density $[13,54]$. The lack of such an extremum in the case of the off-stoichiometric BGGS \pm Se glasses might be due to the fact that the effect of SeSe linkages on density or molar volume of glasses with $z>0$ is offset, at least partially, by the presence of larger and heavier $\mathrm{Ba}$ atoms. This conjecture is borne out by the observation that the increase in density in these glasses is effectively linear with the concentration of Ba (Fig. 10), and hence, it is likely that the heavier $\mathrm{Ba}$ atoms exercise important control on the observed density trends.

\section{Conclusions}

Glasses are synthesized in the system $\mathrm{BaSe}-\mathrm{Ga}_{2} \mathrm{Se}_{3}-\mathrm{GeSe}_{2} \pm \mathrm{Se}$ with off-stoichiometric amounts of Se. As in their stoichiometric $\mathrm{BaSe}-\mathrm{Ga}_{2} \mathrm{Se}_{3}-\mathrm{GeSe}_{2}$ counterparts, the structure of the off-stoichiometric glasses consist of a network of $(\mathrm{Ga} / \mathrm{Ge}) \mathrm{Se}_{4}$ tetrahedra where $\mathrm{Ga}$ and $\mathrm{Ge}$ are four-fold coordinated and Se is two-fold coordinated. Raman and NMR spectroscopic results indicate that in glasses with BaSe: $\mathrm{Ga}_{2} \mathrm{Se}_{3}>1$, the Se-excess induces the formation of homopolar Se-Se bonds while Se-deficiency results in the appearance of homopolar Ge-Ge bonds. Moreover, the concentration of edge-sharing tetrahedral configurations is maximized at stoichiometric compositions. These observations are consistent with the continuously-alloyed 
scenario of chalcogenide glasses and can explain the compositional variation of density and glass transition temperature. Finally, the stoichiometry and the ionic vs. covalent nature of the structural network are shown to play key roles in controlling the composition-dependent mode of Se incorporation in the structure of these glasses.

\section{Acknowledgements:}

The authors thank Steven Currie at Corning Inc. for his help with glass synthesis. This work was supported by the National Science Foundation grant DMR GOALI-1104869. 


\section{References}

[1] B. Bureau, X.H. Zhang, F. Smektala, J.-L. Adam, J. Troles, H.-L. Ma, C. Boussard-Plédel, J. Lucas, P. Lucas, D. Le Coq, M.R. Riley, J.H. Simmons, Recent Advances in Chalcogenide Glasses, J. Non-Cryst. Solids 345-346 (2004) 276-283.

[2] B.J. Eggleton, B. Luther-Davies, K. Richardson, Chalcogenide Photonics, Nat. Photonics 5 (2011) 141-148.

[3] M. Frumar, T. Wagner, Ag Doped Chalcogenide Glasses and their Applications, Curr. Opin. Solid State Mater. Sci. 7 (2003) 117-126.

[4] P.N. Kumta, S.H. Risbud, Review: Rare-Earth Chalcogenides - An Emerging Class of Optical Materials, J. Mater. Sci. 29 (1994) 1135-1158.

[5] J.S. Sanghera, I.D. Aggarwal, Active and Passive Chalcogenide Glass Optical Fibers for IR Applications: A Review, J. Non-Cryst. Solids 256-257 (1999) 6-16.

[6] A. Zakery, S.R. Elliott, Optical Properties and Applications of Chalcogenide Glasses: A Review, J. Non-Cryst. Solids 330 (2003) 1-12.

[7] A. Bytchkov, G.J. Cuello, S. Kohara, C.J. Benmore, D.L. Price, E. Bychkov, Unraveling the Atomic Structure of Ge-Rich Sulfide Glasses, Phys. Chem. Chem. Phys. 15 (2013) 84878494.

[8] A. Giridhar, S. Mahadevan, The Tg Versus Z Dependence of Glasses of the Ge-In-Se System, J. Non-Cryst. Solids 151 (1992) 245-252.

[9] E.L. Gjersing, S. Sen, B.G. Aitken, Structure, Connectivity, and Configurational Entropy of $\mathrm{Ge}_{\mathrm{x}} \mathrm{Se}_{100-\mathrm{x}}$ Glasses: Results from ${ }^{77} \mathrm{Se}$ MAS NMR Spectroscopy, J. Phys. Chem. C 114 (2010) 8601-8608. 
[10] S. Sen, S. Soyer-Uzun, C.J. Benmore, B.G. Aitken, Structure, Topology and Chemical Order in Ge-As-Te glasses: A High-Energy X-Ray Diffraction Study, J. Phys. Condens. Mat. 22 (2010).

[11] U. Senapati, A.K. Varshneya, Viscosity of Chalcogenide Glass-Forming Liquids: An Anomaly in the 'Strong' and 'Fragile' Classification, J. Non-Cryst. Solids 197 (1996) 210-218.

[12] G. Yang, B. Bureau, T. Rouxel, Y. Gueguen, O. Gulbiten, C. Roiland, E. Soignard, J.L. Yarger, J. Troles, J.-C. Sangleboeuf, P. Lucas, Correlation Between Structure and Physical Properties of Chalcogenide Glasses in the $\mathrm{As}_{\mathrm{x}} \mathrm{Se}_{1-\mathrm{x}}$ System, Phys. Rev. B 82 (2010) 195206-195206.

[13] G. Yang, Y. Gueguen, J.-C. Sangleboeuf, T. Rouxel, C. Boussard-Plédel, J. Troles, P. Lucas, B. Bureau, Physical Properties of the $\mathrm{Ge}_{x} \mathrm{Se}_{1-x}$ Glasses in the $0<\mathrm{x}<0.42$ Range in Correlation with Their Structure, J. Non-Cryst. Solids 377 (2013) 54-59.

[14] B.G. Aitken, R.S. Quimby, Rare-Earth-Doped Multicomponent Ge-Based Sulphide Glasses, J. Non-Cryst. Solids 213-214 (1997) 281-287.

[15] S. Barnier, M. Guittard, C. Julien, Glass Formation and Structural Studies of Chalcogenide Glasses in the CdS-Ga ${ }_{2} \mathrm{~S}_{3}-\mathrm{GeS}_{2}$ System, Mater. Sci. Eng. B 7 (1990) 209-214.

[16] H. Haeuseler, C. Schmidt, Glass Formation in the System $\mathrm{BaS}-\mathrm{Ga}_{2} \mathrm{~S}_{3}-\mathrm{GeS}_{2}$ and the Structure of $\mathrm{Ba}_{2.7} \mathrm{Ga}_{5.4} \mathrm{Ge}_{3.6} \mathrm{~S}_{18}$, J. Alloys Compd. 204 (1994) 209-213.

[17] B.B. Harbison, C.I. Merzbacher, I.D. Aggarwal, Preparation and Properties of $\mathrm{BaS}_{-} \mathrm{Ga}_{2} \mathrm{~S}_{3^{-}}$ $\mathrm{GeS}_{2}$ Glasses, J. Non-Cryst. Solids 213 (1997) 16-21. 
[18] C. Julien, S. Barnier, M. Massot, N. Chbani, X. Cai, A.M. Loireau-Lozac'h, M. Guittard, Raman and Infrared Spectroscopic Studies of Ge-Ga-Ag Sulphide Glasses, Mater. Sci. Eng. B 22 (1994) 191-200.

[19] L. Koudelka, M. Pisarcik, O. Baidakova, The Effect of MnS- and $\mathrm{MnCl}_{2}$-Doping on the Structure of $\mathrm{GeS}_{2}-\mathrm{Ga}_{2} \mathrm{~S}_{3}$ Glasses, J. Mater. Sci. Lett. 8 (1989) 1161-1162.

[20] J. Saienga, S.W. Martin, The Comparative Structure, Properties, and Ionic Conductivity of $\mathrm{LiI}+\mathrm{Li}_{2} \mathrm{~S}+\mathrm{GeS}_{2}$ Glasses Doped with $\mathrm{Ga}_{2} \mathrm{~S}_{3}$ and $\mathrm{La}_{2} \mathrm{~S}_{3}$, J. Non-Cryst. Solids 354 (2008) $1475-1486$.

[21] J.D. Shephard, R.I. Kangley, R.J. Hand, D. Furniss, C.A. Miller, A.B. Seddon, Properties of Ga-La-Na Sulphide Glasses, J. Non-Cryst. Solids 332 (2003) 271-278.

[22] S. Sen, R.E. Youngman, High-Resolution Multinuclear NMR Structural Study of Binary Aluminosilicate and Other Related Glasses, J. Phys. Chem. B 108 (2004) 7557-7564.

[23] A.W. Mao, B.G. Aitken, S. Sen, Synthesis and Physical Properties of Chalcogenide Glasses in the System BaSe- $\mathrm{Ga}_{2} \mathrm{Se}_{3}-\mathrm{GeSe}_{2}$, J. Non-Cryst. Solids 369 (2013) 38-43.

[24] A.W. Mao, B.G. Aitken, R.E. Youngman, D.C. Kaseman, S. Sen, Structure of Glasses in the Pseudobinary System $\mathrm{Ga}_{2} \mathrm{Se}_{3}-\mathrm{GeSe}_{2}$ : Violation of Chemical Order and 8-N Coordination Rule, J. Phys. Chem. B 117 (2013) 16594-16601.

[25] A.W. Mao, D.C. Kaseman, R.E. Youngman, B.G. Aitken, S. Sen, Structure and Bonding Characteristics of Chalcogenide Glasses in the System BaSe- $\mathrm{Ga}_{2} \mathrm{Se}_{3}-\mathrm{GeSe}_{2}$, J. Non-Cryst. Solids 375 (2013) 40-46.

[26] A.W. Mao, S.C. Currie, B.G. Aitken, S. Sen, Synthesis and Characterization of Ternary Glasses in the System $\mathrm{Na}_{2} \mathrm{Se}_{-} \mathrm{Ga}_{2} \mathrm{Se}_{3}-\mathrm{GeSe}_{2}$, J. Non-Cryst. Solids 404 (2014) 91-97. 
[27] A.W. Mao, D.C. Kaseman, I. Hung, Z. Gan, B.G. Aitken, S. Sen, Mechanisms of Structural Accommodation of Se Deficiency in Binary $\mathrm{Ga}_{2} \mathrm{Se}_{3}-\mathrm{GeSe}_{2}$ Glasses: Results from ${ }^{77} \mathrm{Se}$ MATPASS/CPMG NMR Spectroscopy, J. Non-Cryst. Solids 410 (2015) 14-19.

[28] M.J. Collins, C.I. Ratcliffe, J.A. Ripmeester, CP/MAS ${ }^{77}$ Se NMR in Solids, Chemical Shift Tensors and Isotropic Shifts, J. Magn. Reson. 68 (1986) 172-179.

[29] I. Hung, Z. Gan, A Magic-Angle Turning NMR Experiment for Separating Spinning Sidebands of Half-Integer Quadrupolar Nuclei, Chem. Phys. Lett. 496 (2010) 162-166.

[30] X. Lin, Y. Guo, N. Ye, $\mathrm{BaGa}_{2} \mathrm{GeX}_{6}(\mathrm{X}=\mathrm{S}$, Se): New Mid-IR Nonlinear Optical Crystals with Large Band Gaps, J. Solid State Chem. 195 (2012) 172-177.

[31] W. Yin, K. Feng, R. He, D. Mei, Z. Lin, J. Yao, Y. Wu, BaGa $\mathrm{MQ}_{6}(\mathrm{M}=\mathrm{Si}, \mathrm{Ge} ; \mathrm{Q}=\mathrm{S}, \mathrm{Se})$ : A New Series of Promising IR Nonlinear Optical Materials, Dalton Trans. 41 (2012) $5653-5661$.

[32] A. Assoud, N. Soheilnia, H. Kleinke, From Yellow to Black: New Semiconducting Ba Chalcogeno-Germanates, Z. Naturforsch. 59b (2004) 975-979.

[33] D. Johrendt, M. Tampier, Strontium Selenogermanate (III) and Barium Selenogermanate (II, IV): Synthesis, Crystal Structures, and Chemical Bonding, Chem. Eur. J. 6 (2000) 994998.

[34] V.W. Klee, H. Schafer, Darstellung und Struktur von $\mathrm{BaAl}_{2} \mathrm{Se}_{4}, \mathrm{BaGa}_{2} \mathrm{Se}_{4}, \mathrm{CaGa}_{2} \mathrm{Se}_{4}$ und Caln $\mathrm{Te}_{4}$, Z. Anorg. Allg. Chem. 133 (1981) 125-133.

[35] J. Yao, D. Mei, L. Bai, Z. Lin, W. Yin, P. Fu, Y. Wu, BaGa ${ }_{4} \mathrm{Se}_{7}$ : A New Congruent-Melting IR Nonlinear Optical Material, Inorg. Chem. 49 (2010) 9212-9216.

[36] J. Yao, W. Yin, K. Feng, X. Li, D. Mei, Q. Lu, Y. Ni, Z. Zhang, Z. Hu, Y. Wu, Growth and Characterization of $\mathrm{BaGa}_{4} \mathrm{Se}_{7}$ Crystal, J. Cryst. Growth 346 (2012) 1-4. 
[37] D. Mei, W. Yin, Z. Lin, R. He, J. Yao, P. Fu, Y. Wu, Syntheses and Characterization of Two New Selenides $\mathrm{Ba}_{5} \mathrm{Al}_{2} \mathrm{Se}_{8}$ and $\mathrm{Ba}_{5} \mathrm{Ga}_{2} \mathrm{Se}_{8}$, J. Alloys Compd. 509 (2011) 2981-2985.

[38] W. Yin, D. Mei, K. Feng, J. Yao, P. Fu, Y. Wu, Ba $\mathrm{Ga}_{4} \mathrm{Se}_{10}$ : A New Selenidogallate Containing the Novel $\left[\mathrm{Ga}_{4} \mathrm{Se}_{10}\right]^{10-}$ Anionic Cluster with Ga in a Mixed-Valence State, Dalton Trans. 40 (2011) 9159-9162.

[39] K. Maeda, T. Sakai, K. Sakai, T. Ikari, M. Munzar, D. Tonchev, S.O. Kasap, G. Lucovsky, Effect of Ga on the Structure of Ge-Se-Ga Glasses from Thermal Analysis, Raman and XPS Measurements, J. Mater. Sci. Mater. Electron. 18 (2007) 367-370.

[40] M. Munzar, K. Koughia, D. Tonchev, S.O. Kasap, T. Sakai, K. Maeda, T. Ikari, C. Haugen, R. Decorby, J.N. McMullin, Influence of Ga on the Optical and Thermal Properties of $\mathrm{Er}_{2} \mathrm{~S}_{3}$ Doped Stoichiometric and Nonstoichiometric Ge-Ga-Se Glasses, Phys. Chem. Glasses B 46 (2005) 215-219.

[41] P. Nemec, B. Frumarová, M. Frumar, Structure and Properties of the Pure and $\operatorname{Pr}^{3+}$-Doped $\mathrm{Ge}_{25} \mathrm{Ga}_{5} \mathrm{Se}_{70}$ and $\mathrm{Ge}_{30} \mathrm{Ga}_{5} \mathrm{Se}_{65}$ Glasses, J. Non-Cryst. Solids 270 (2000) 137-146.

[42] T.G. Edwards, S. Sen, E.L. Gjersing, A Combined ${ }^{77}$ Se NMR and Raman Spectroscopic Study of the Structure of $\mathrm{Ge}_{\mathrm{x}} \mathrm{Se}_{1-\mathrm{x}}$ Glasses: Towards a Self Consistent Structural Model, J. Non-Cryst. Solids 358 (2012) 609-614.

[43] J.-B. d'Espinose de Lacaillerie, C. Fretigny, D. Massiot, MAS NMR Spectra of Quadrupolar Nuclei in Disordered Solids: The Czjzek Model, J. Magn. Reson. 192 (2008) 244-251.

[44] G. Le Caër, B. Bureau, D. Massiot, An Extension of the Czjzek Model for the Distributions of Electric Field Gradients in Disordered Solids and an Application to NMR Spectra of ${ }^{71} \mathrm{Ga}$ in Chalcogenide Glasses, J. Phys. Condens. Mat. 22 (2010) 065402-065402. 
[45] D. Massiot, F. Fayon, M. Capron, I. King, S. Le Calvé, B. Alonso, J.O. Durand, B. Bujoli, Z. Gan, G. Hoatson, Modelling One- and Two-Dimensional Solid-State NMR Spectra, Magn. Reson. Chem. 40 (2002) 70-76.

[46] R. Golovchak, L. Calvez, E. Petracovschi, B. Bureau, D. Savytskii, H. Jain, Incorporation of Ga into the Structure of Ge-Se Glasses, Mater. Chem. Phys. 138 (2013) 909-916.

[47] T. Ishibashi, H. Takebe, K. Morinaga, Glass Forming Region and Structure of Vitreous RS$\mathrm{Ga}_{2} \mathrm{~S}_{3}(\mathrm{R}=\mathrm{Ca}, \mathrm{Sr}, \mathrm{Ba})$, J. Ceram. Soc. Jpn. 111 (2003) 308-311.

[48] A. Kuhn, A. Chevy, R. Chevalier, Crystal Structure and Interatomic Distances in GaSe, Phys. Status Solidi A 31 (1975) 469-475.

[49] B.G. Aitken, C.W. Ponader, R.S. Quimby, Clustering of Rare Earths in GeAs Sulfide Glass, C. R. Chim. 5 (2002) 865-872.

[50] Y.G. Choi, Spatial Distribution of Rare-Earth Ions in Se-Based Chalcogenide Glasses with or without Ga, J. Non-Cryst. Solids 353 (2007) 1930-1935.

[51] S. Benazeth, M.H. Tuilier, A.-M. Loireau-Lozac'h, H. Dexpert, P. Lagarde, J. Flahaut, An EXAFS Structural Approach of the Lanthanum-Gallium-Sulfur Glasses, J. Non-Cryst. Solids 110 (1989) 89-100.

[52] L. Calvez, P. Lucas, M. Rozé, H.L. Ma, J. Lucas, X.H. Zhang, Influence of Gallium and Alkali Halide Addition on the Optical and Thermo-Mechanical Properties of $\mathrm{GeSe}_{2}$ $\mathrm{Ga}_{2} \mathrm{Se}_{3}$ Glass, Appl. Phys. A 89 (2007) 183-188.

[53] Y. Nedeva, T. Petkova, E. Mytilineou, P. Petkov, Compositional Dependence of the Optical Properties of the Ge-Se-Ga Glasses, J. Optoelectron. Adv. M. 3 (2001) 433-436.

[54] S. Mahadevan, A. Giridhar, Coexistence of Topological and Chemical Ordering Effects in Ge-Ga-Se Glasses, J. Non-Cryst. Solids 152 (1993) 42-49. 


\section{Figures:}

Table 1: Summary of the nominal compositions of all samples synthesized (see also Figure 1). The state of each sample after quenching is denoted G for glassy and GC for partially devitrified glass.

\begin{tabular}{|c|c|c|c|c|c|c|c|c|}
\hline \multicolumn{4}{|c|}{ Nominal composition (mole \%) } & \multicolumn{4}{|c|}{ Atom $\%$ of constituent elements } & \multirow[t]{2}{*}{ State } \\
\hline BaSe (x) & $\mathrm{Ga}_{2} \mathrm{Se}_{3}$ & $\mathrm{GeSe}_{2}(\mathrm{y})$ & $\mathrm{z}(\mathrm{mol} \%)$ & $\mathbf{B a}$ & Ga & Ge & Se & \\
\hline 5 & 20 & 75 & 20 & 1.32 & 10.58 & 19.84 & 68.25 & G \\
\hline 5 & 20 & 75 & -10 & 1.59 & 12.76 & 23.92 & 61.72 & GC \\
\hline 5 & 20 & 75 & -20 & 1.71 & 13.70 & 25.68 & 58.90 & GC \\
\hline 12.5 & 12.5 & 75 & 20 & 3.55 & 7.09 & 21.28 & 68.09 & G \\
\hline 12.5 & 12.5 & 75 & -20 & 4.59 & 9.17 & 27.52 & 58.72 & GC \\
\hline 20 & 5 & 75 & 20 & 6.12 & 3.06 & 22.94 & 67.89 & G \\
\hline 20 & 5 & 75 & 10 & 6.48 & 3.24 & 24.31 & 65.96 & $\mathrm{G}$ \\
\hline 20 & 5 & 75 & -10 & 7.37 & 3.68 & 27.62 & 61.33 & $\mathrm{G}$ \\
\hline 20 & 5 & 75 & -20 & 7.91 & 3.95 & 29.64 & 58.50 & $\mathrm{G}$ \\
\hline 20 & 5 & 75 & -30 & 8.53 & 4.26 & 31.98 & 55.22 & $\mathrm{G}$ \\
\hline 20 & 5 & 75 & -40 & 9.26 & 4.63 & 34.72 & 51.39 & GC \\
\hline 7.5 & 32.5 & 60 & 20 & 1.86 & 16.15 & 14.91 & 67.08 & GC \\
\hline 7.5 & 32.5 & 60 & -10 & 2.24 & 19.40 & 17.91 & 60.45 & GC \\
\hline 32.5 & 7.5 & 60 & 20 & 10.24 & 4.72 & 18.90 & 66.14 & G \\
\hline 32.5 & 7.5 & 60 & 10 & 10.83 & 5.00 & 20.00 & 64.17 & $\mathrm{G}$ \\
\hline 32.5 & 7.5 & 60 & -10 & 12.26 & 5.66 & 22.64 & 59.43 & $\mathrm{G}$ \\
\hline 32.5 & 7.5 & 60 & -20 & 13.13 & 6.06 & 24.24 & 56.57 & $\mathrm{G}$ \\
\hline 32.5 & 7.5 & 60 & -30 & 14.13 & 6.52 & 26.09 & 53.26 & GC \\
\hline 32.5 & 7.5 & 60 & -40 & 15.29 & 7.06 & 28.24 & 49.41 & GC \\
\hline 15 & 25 & 60 & 20 & 3.98 & 13.26 & 15.92 & 66.84 & GC \\
\hline 15 & 25 & 60 & -20 & 5.12 & 17.06 & 20.48 & 57.34 & GC \\
\hline 25 & 15 & 60 & 20 & 7.29 & 8.75 & 17.49 & 66.47 & GC \\
\hline 25 & 15 & 60 & -20 & 9.36 & 11.24 & 22.47 & 56.93 & GC \\
\hline
\end{tabular}




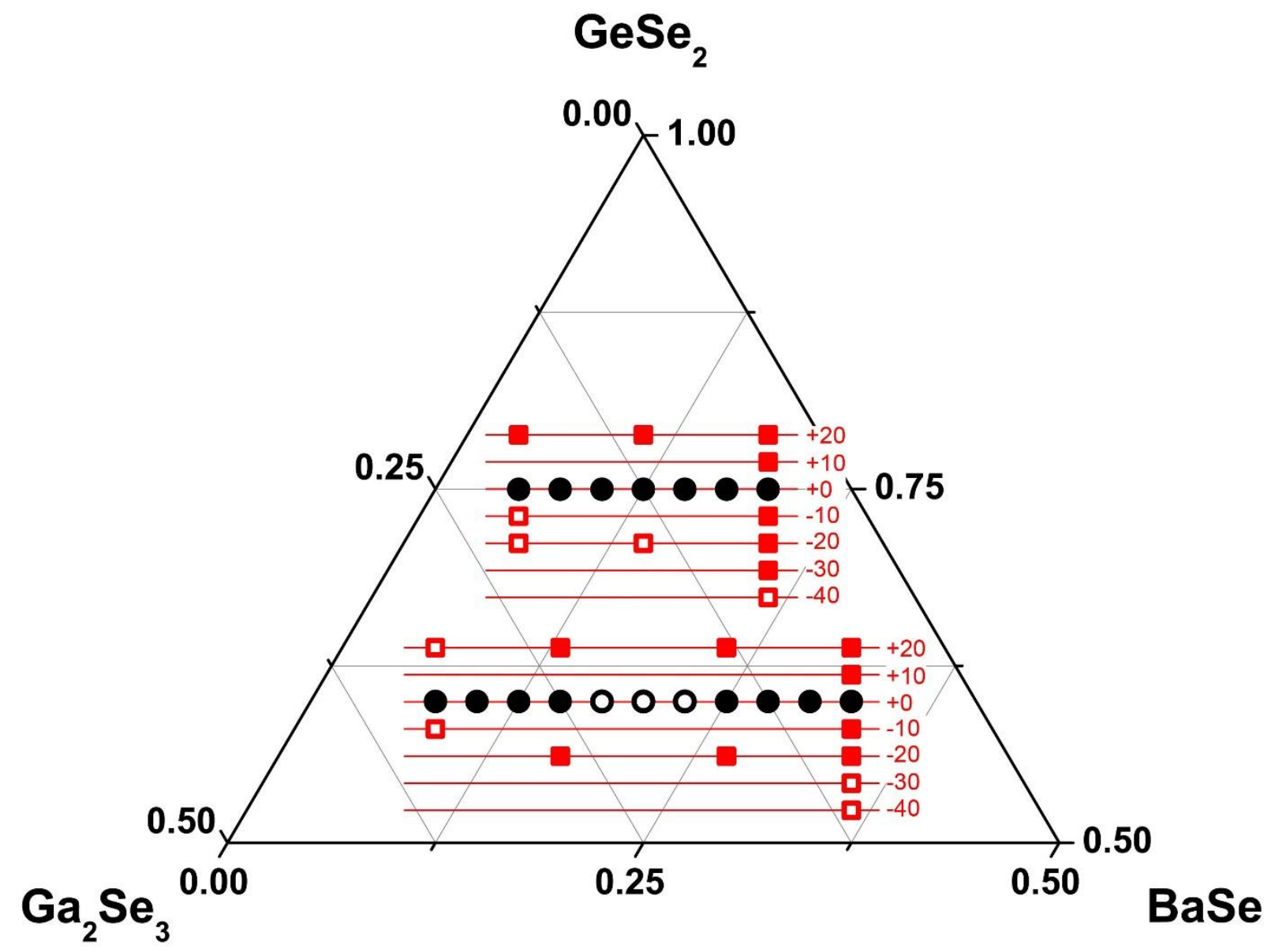

Figure 1: 2D representation of the tentative glass-forming region for stoichiometric BGGS (black symbols) and off-stoichiometric BGGS \pm Se (red symbols) glasses. The compositions for black symbols can be read from the outer ternary diagram [23, 25]. Red squares represent offstoichiometric series based on the two horizontal stoichiometric composition lines with 75 and $60 \mathrm{~mol} \% \mathrm{GeSe}_{2}$. The off-stoichiometric compositions are above or below the ternary plane and are denoted by the $\mathrm{z}$ value alongside the horizontal lines. Filled and open symbols correspond to glassy and partially devitrified samples, respectively. 


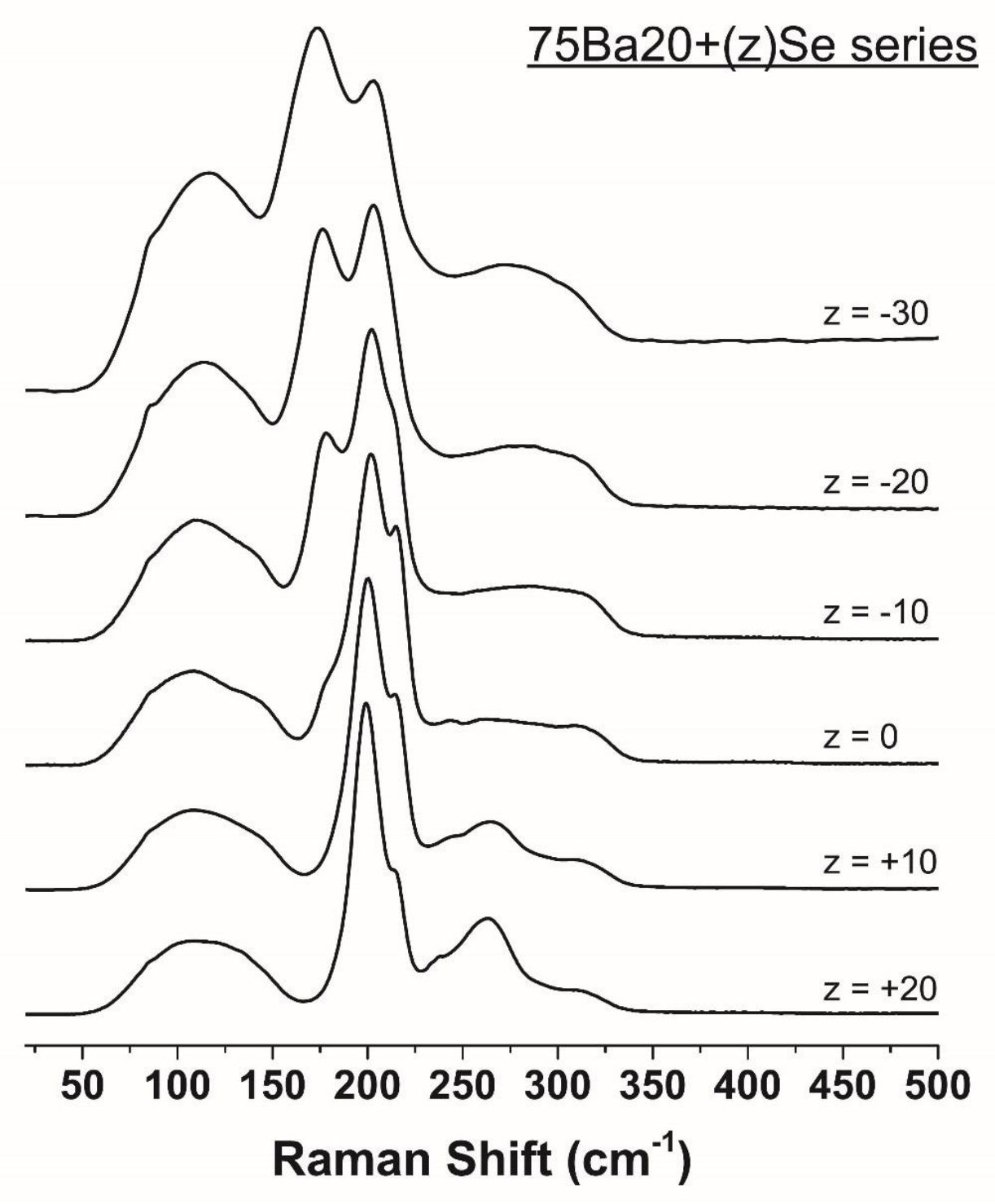

Figure 2: Raman spectra of $\mathrm{BGGS} \pm$ Se glasses in the $75 \mathrm{Ba} 20+(\mathrm{z})$ Se series. Values of $\mathrm{z}$ are denoted alongside the spectra. 


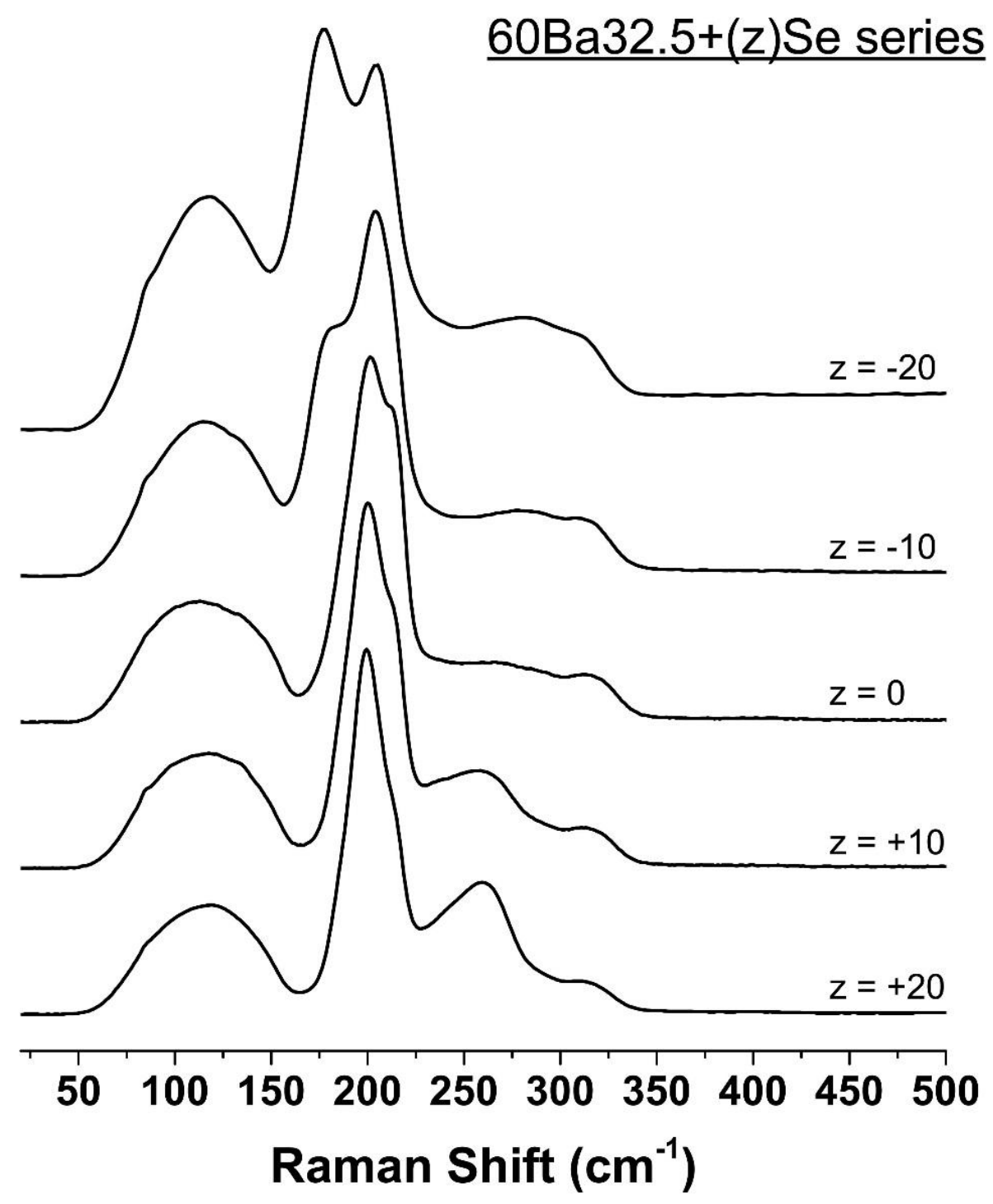

Figure 3: Raman spectra of $\mathrm{BGGS} \pm$ Se glasses in the $60 \mathrm{Ba} 32.5+(\mathrm{z})$ Se series. Values of $\mathrm{z}$ are denoted alongside the spectra. 


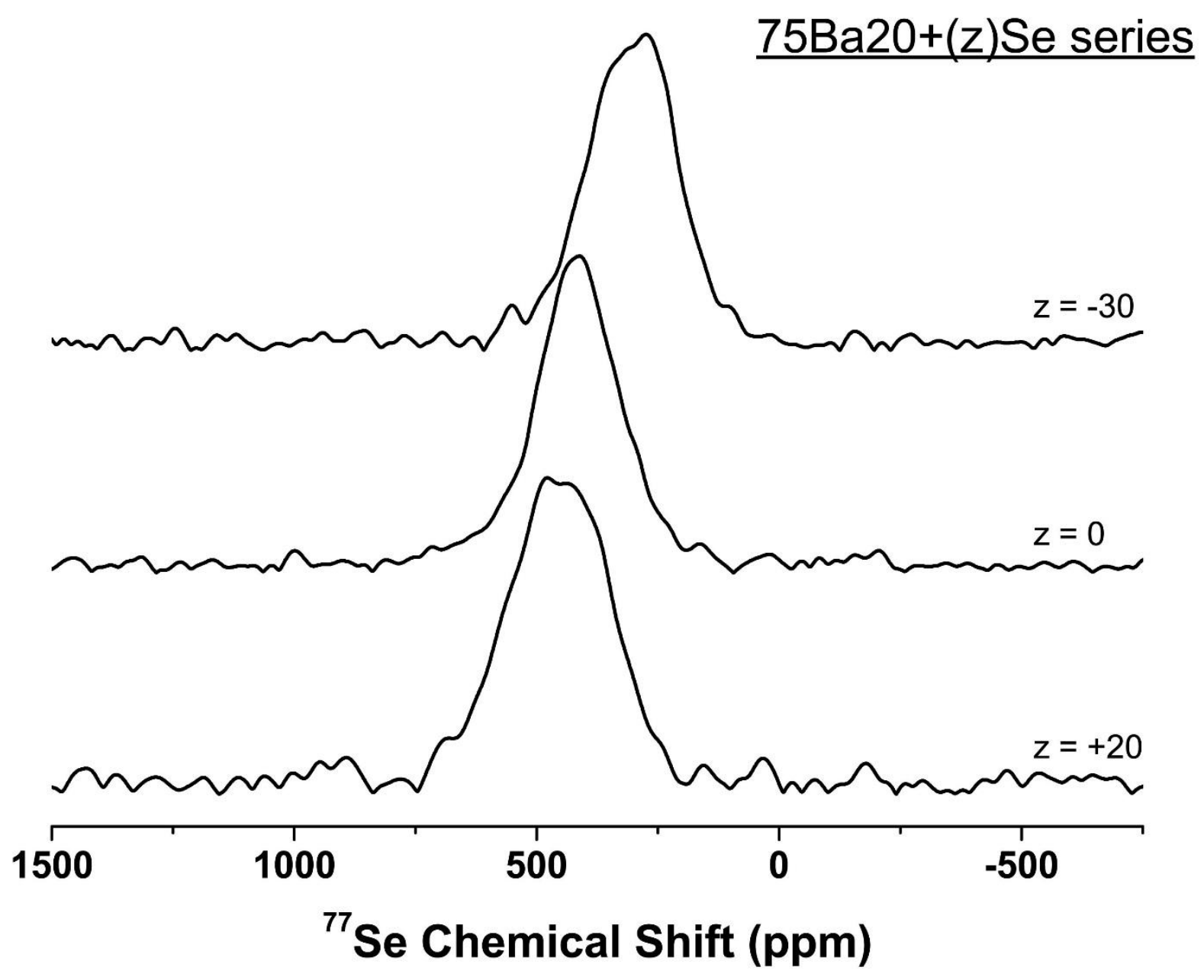

Figure 4: ${ }^{77}$ Se MAS NMR spectra of select BGGS \pm Se glasses in the $75 \mathrm{Ba} 20+(\mathrm{z}) \mathrm{Se}$ series. Values of $\mathrm{z}$ are denoted alongside the spectra. 


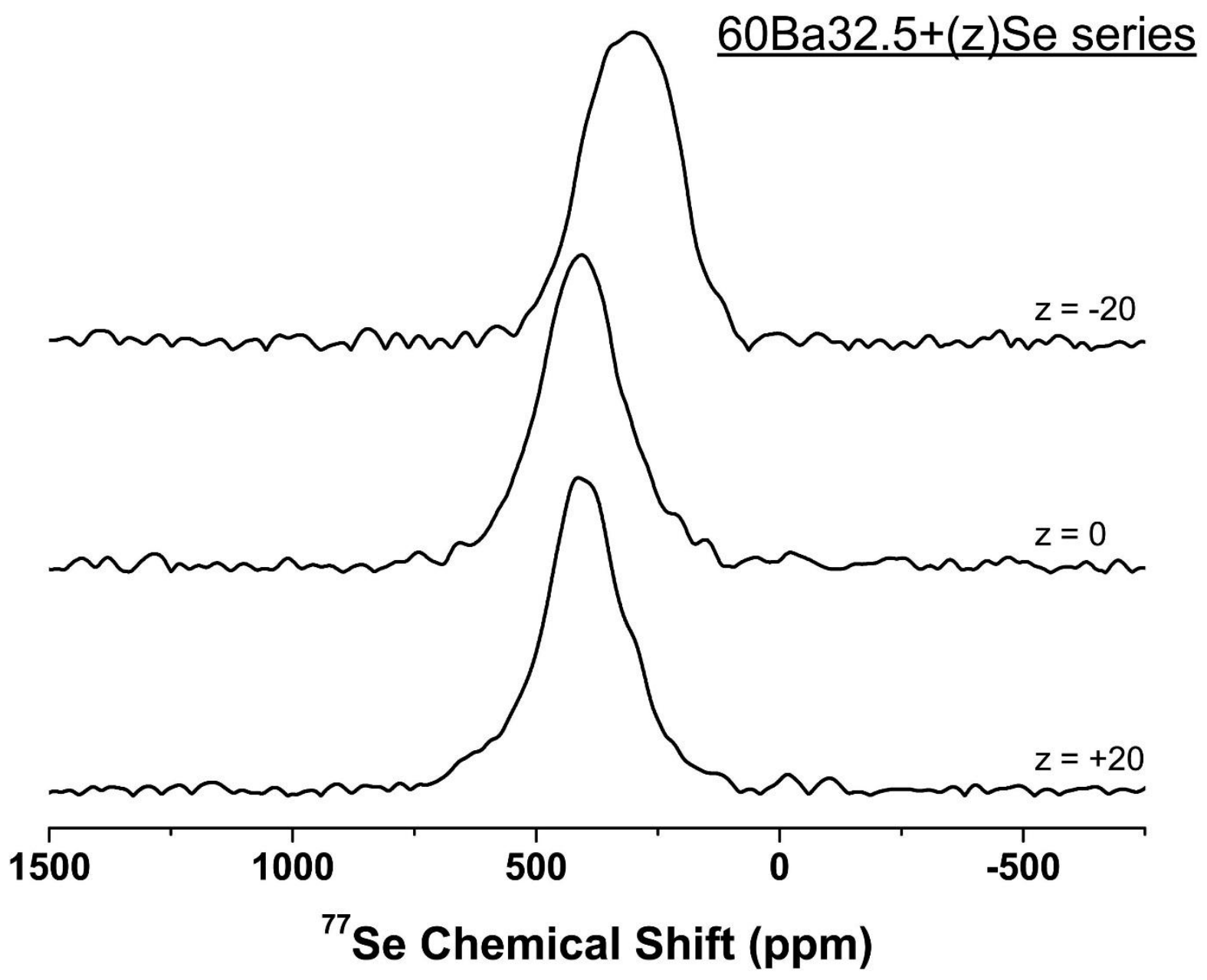

Figure 5: ${ }^{77}$ Se MAS NMR spectra of select BGGS \pm Se glasses in the $60 \mathrm{Ba} 32.5+(\mathrm{z}) \mathrm{Se}$ series. Values of $\mathrm{z}$ are denoted alongside the spectra. 


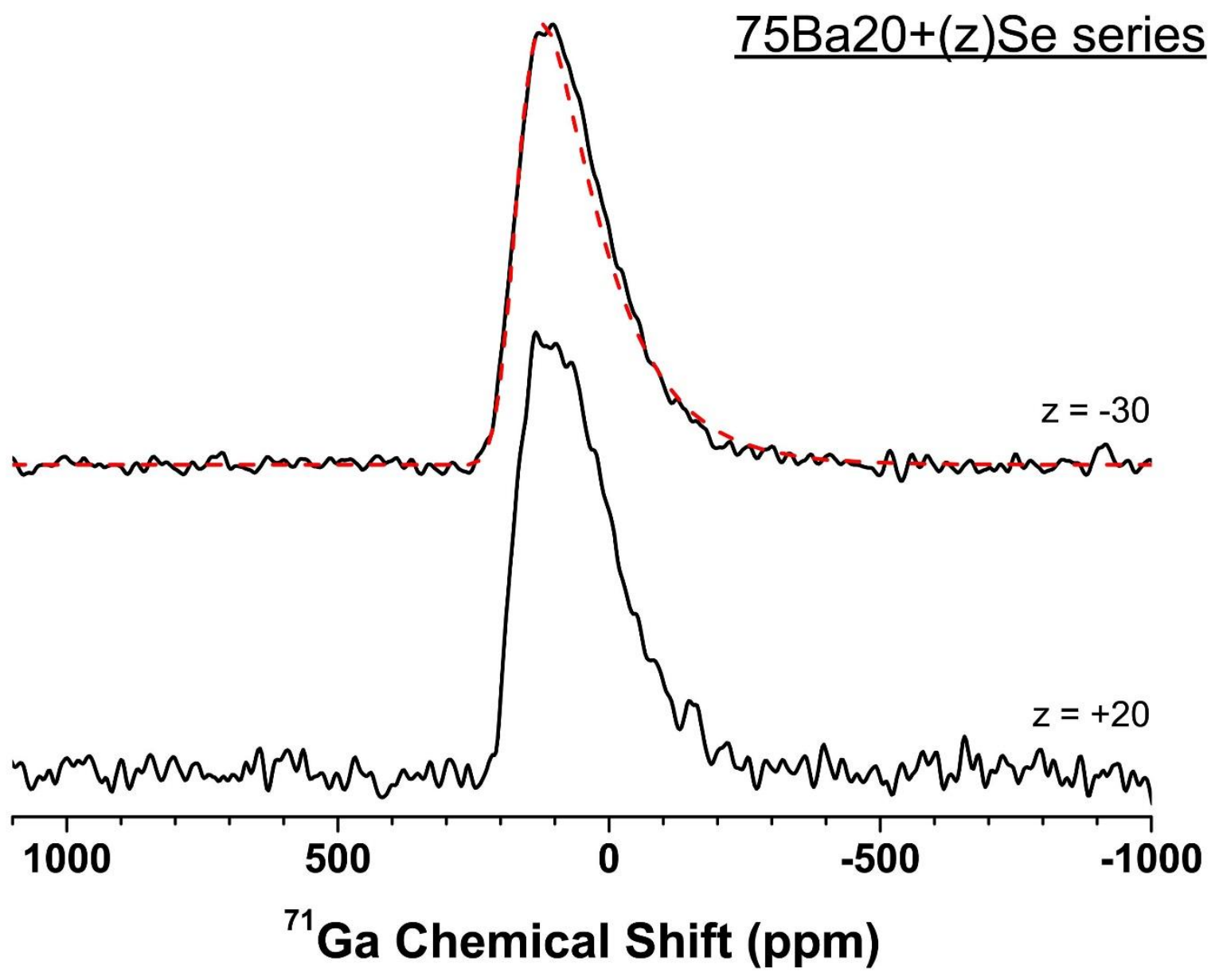

Figure 6: ${ }^{71} \mathrm{Ga}$ central transition QMAT NMR spectra of select $\mathrm{BGGS} \pm$ Se glasses in the $75 \mathrm{Ba} 20+(\mathrm{z})$ Se series. A representative simulation of the line shape using the Czjzek model is also shown (dashed red line). Values of $\mathrm{z}$ are denoted alongside the spectra. 


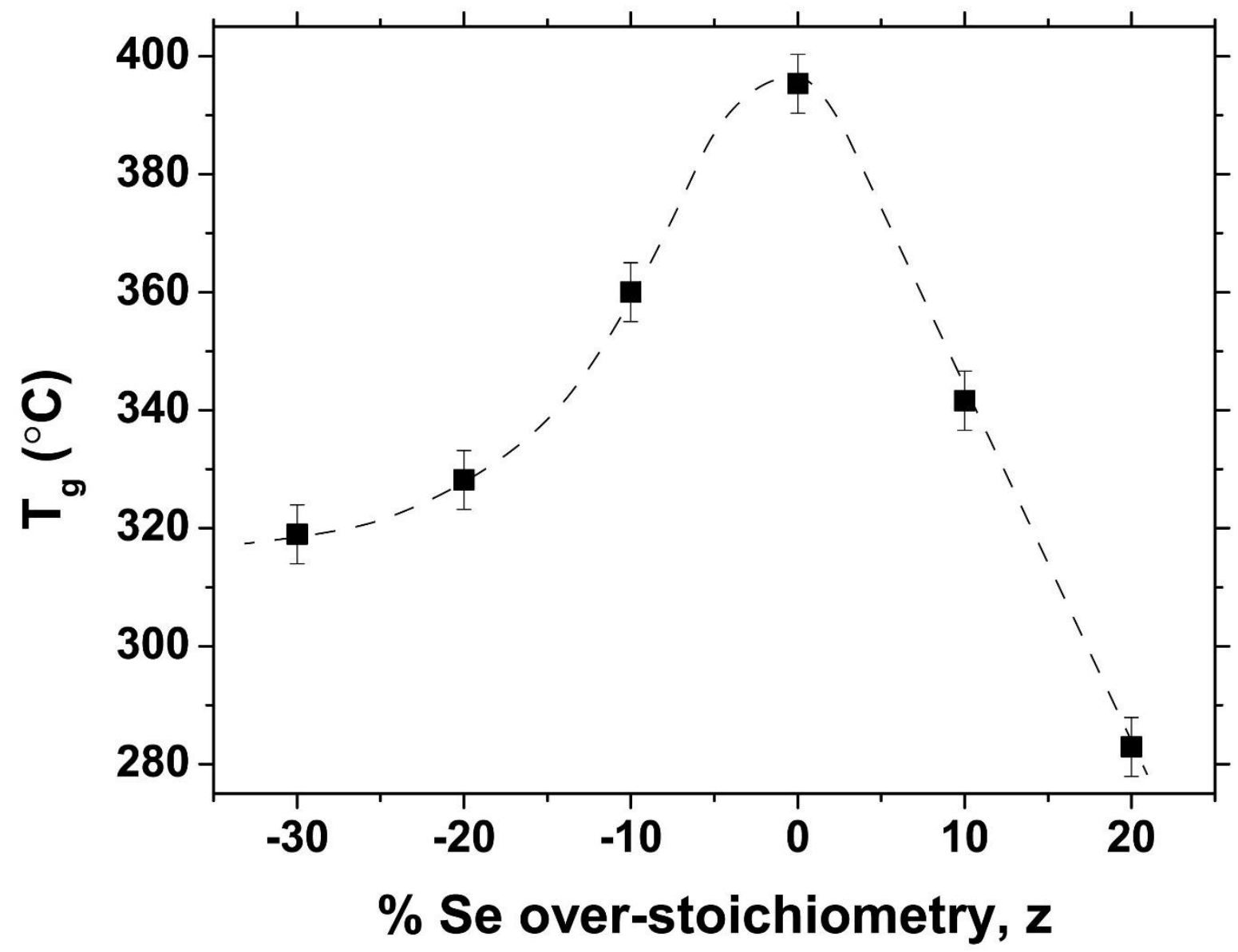

Figure 7: Glass transition temperature of glasses in the $75 \mathrm{Ba} 20+(\mathrm{z}) \mathrm{Se}$ series as a function of $\mathrm{z}$. The dashed line serves as a guide for the eye. 


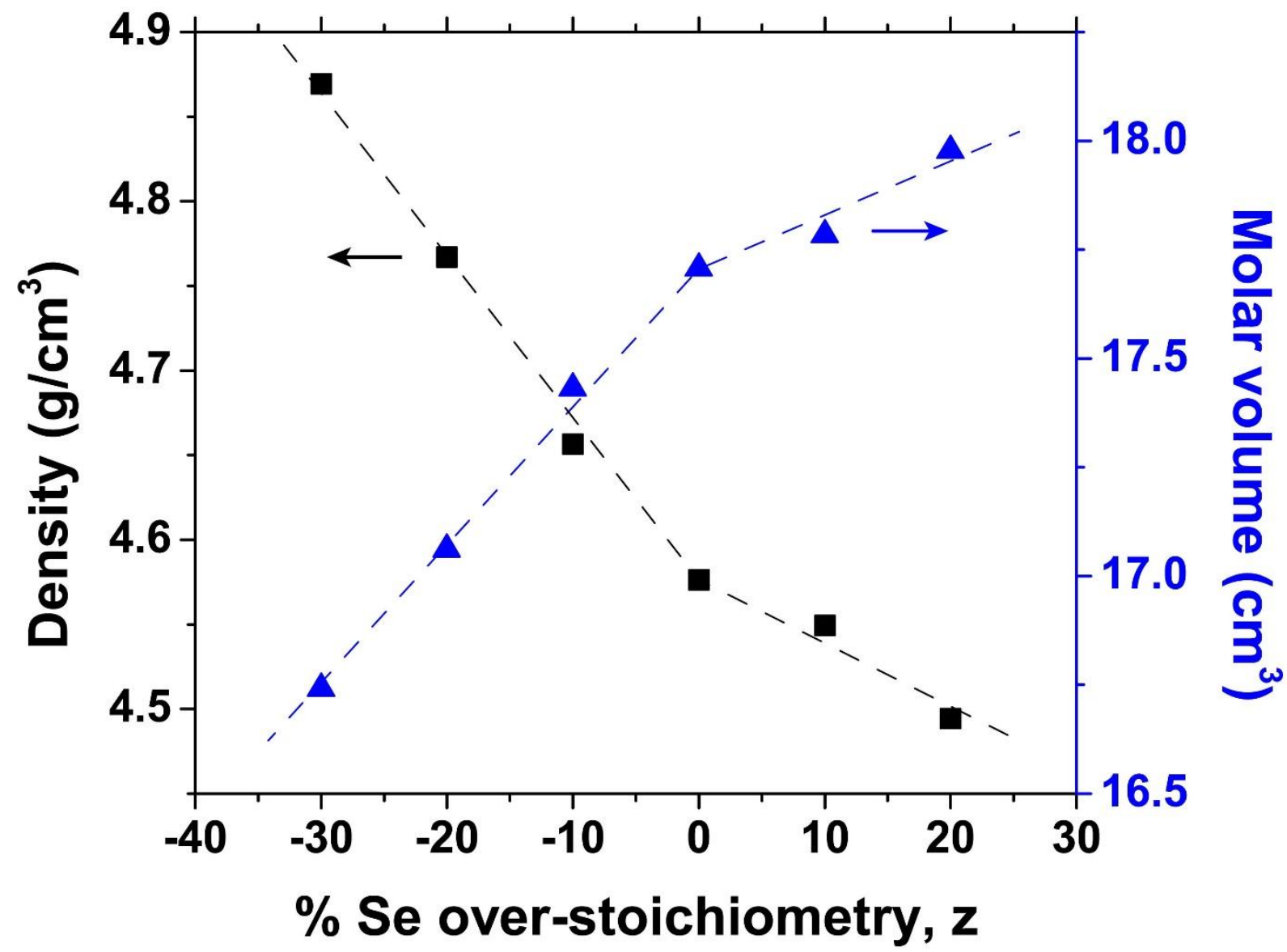

Figure 8: Density (black $\mathbf{\square})$ and molar volume (blue $\mathbf{\Delta}$ ) of glasses in the $75 \mathrm{Ba} 20+(\mathrm{z}) \mathrm{Se}$ series as a function of $\mathrm{z}$. The dashed lines serve as a guide for the eye. 


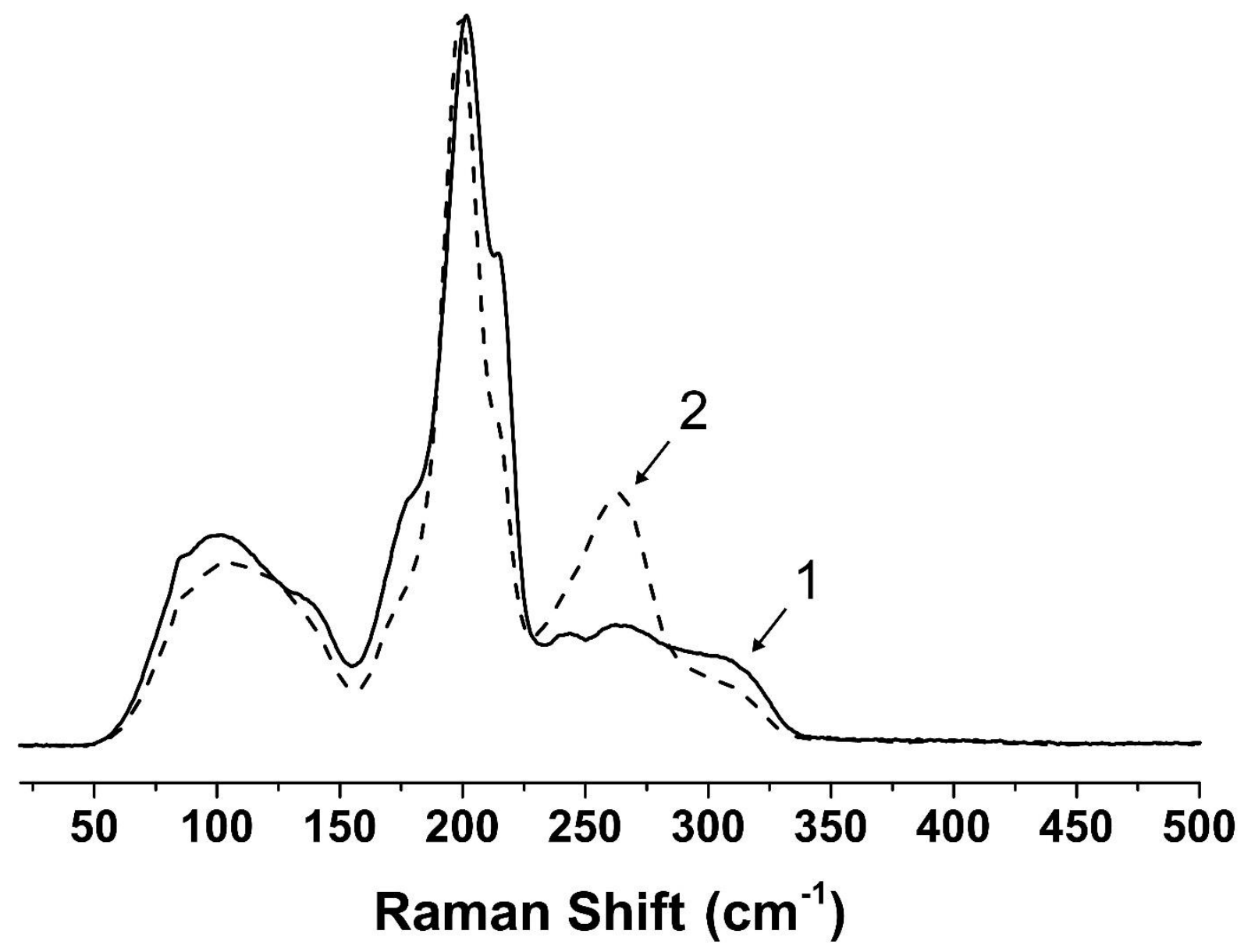

Figure 9: Raman spectra of $\mathrm{BGGS} \pm$ Se glasses (1) 75Ba5+0Se (solid line) and (2) 75Ba5+20Se (dashed line). Note the decrease (increase) in the intensity of the band near $175 \mathrm{~cm}^{-1}\left(265 \mathrm{~cm}^{-1}\right)$ upon addition of excess Se. 


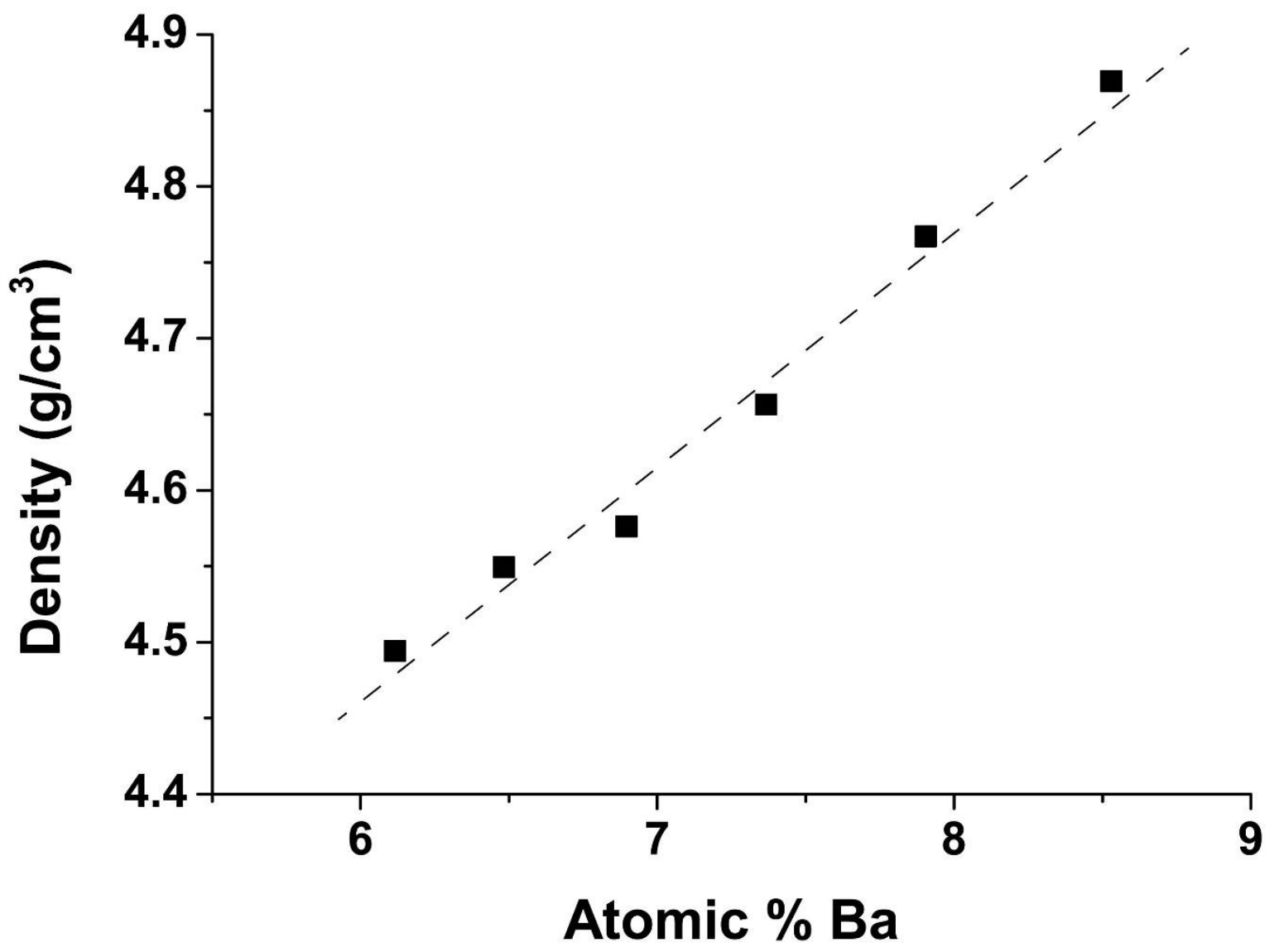

Figure 10: Density of glasses in the $75 \mathrm{Ba} 20+(\mathrm{z})$ Se series as a function of the $\mathrm{Ba}$ atomic percent. The dashed line serves as a guide for the eye. 